\title{
COLOR TEMPERATURE OF LED LIGHT-EMITTING DIODES LIGHTING DEVICES AND PRODUCTIVITY OF LAYING HENS
}

\author{
Dmitry Gladin ${ }^{1, *}$, and Alexey Kavtarashvili² \\ ${ }^{1}$ LTD "TECHNOSVET GROUP", Russia \\ ${ }^{2}$ Laboratory of the Technology of Egg Production, Federal Scientific Center "All-Russian Research and Technological Institute of \\ Poultry" of Russian Academy of Sciences, Sergiev Posad, Russia
}

\begin{abstract}
The article is devoted to the study of the influence of different modes of LED lamps color temperature in high-speed lighting conditions $2 \mathrm{C}: 5 \mathrm{~T}: 3 \mathrm{C}: 2 \mathrm{~T}: 3 \mathrm{C}: 9 \mathrm{~T}$ on productivity and viability, quality of the cross "Shaver" hens' eggs. 4 modes of color temperature of radiation were tested: in the 1st group-in all periods of light $3000 \mathrm{~K}$; in the 2nd group-the first and last periods of light $3000 \mathrm{~K}$, the average period of light $5000 \mathrm{~K}$; in the $3 \mathrm{rd}$ group-the first and last periods of light $5000 \mathrm{~K}$, the average period of light $3000 \mathrm{~K}$; group 4-the first half of each period of light $3000 \mathrm{~K}$, the second half $5000 \mathrm{~K}$. It was found that in groups 1 , 2, 3 and 4 with high bird safety (99-100\%), egg production per 1 laying hen was 148.6, 141.8, 155.5 and 140.5 pieces; egg weight-61.2, 60.9, 62.3 and $60.9 \mathrm{~g}$; egg weight yield per 1 laying hen-8.99, 8.55, 9.56 and $8.47 \mathrm{~kg}$; feed consumption per $1 \mathrm{~kg}$ of egg weight-3.31, 2.43, 2.24 and $2.40 \mathrm{~kg}$. According to the complex of zootechnical indicators, the 3rd group was recognized as the best, which also surpassed other groups in absolute and relative weight of the yolk (15.04 $\mathrm{g}$ and $24.35 \% \mathrm{vs} .14 .16-15.04 \mathrm{~g}$ and $23.31-24.35 \%$ ), absolute weight of protein $(40.50 \mathrm{~g}$ vs. $38.98-39.88 \mathrm{~g})$ and slightly inferior in absolute and relative weight of the shell (6.73 $\mathrm{g}$ and $10.78 \%$ vs. $6.83-6.92 \mathrm{~g}$ and $11.08-11.39 \%$ ).
\end{abstract}

\section{Introduction}

Light is the most important environmental factor that influences the behavior, physiological state, viability and productivity of birds [1-5]. In conditions of intensive production of eggs and poultry meat, artificial lighting is used as a mechanism that regulates the growth, development and productivity of poultry [6-10]. Consequently, the mode, intensity, spectrum and source of illumination, as well as the color temperature of the radiation, have become the main factors of light in modern poultry farming $[1,5,11,12]$.

The evolution of animals, including birds, took place under the influence of natural light, the color temperature of which varies depending on the time of year, day and state of the atmosphere.

The appearance of LEDs, due to their special characteristics, allows you to significantly change the spectrum and color temperature of radiation in specific lamps. Numerous studies have shown the dependence of the productivity and quality of poultry eggs on the spectrum and color temperature of the source [13-20].

The aim of the study was to study the viability and productivity of laying hens, the quality of food eggs under different modes of color temperature of LED lamps against the background of intermittent daylight.

\section{Materials and methods}

The study was conducted in the vivarium of the selection and genetic center "Zagorsk Experimental breeding farm VNITIP". Of the 140-day-old chickens of the industrial herd of the cross "Sheiver", 4 groups of 100 heads each were formed by the method of analogues. The bird up to 320 days of age was kept in cell batteries with 5 heads per cage. All groups used the same intermittent lighting mode $2 \mathrm{C}: 5 \mathrm{~T}: 3 \mathrm{C}: 2 \mathrm{~T}: 3 \mathrm{C}: 9 \mathrm{~T}$ (the first switching on of the light was carried out at 2 o'clock in the morning, further according to the scheme), the illumination intensity was 10 lux.

Table 1. Research scheme.

\begin{tabular}{|c|l|}
\hline Group & $\begin{array}{l}\text { Mode of the color temperature of the radiation of } \\
\text { the LED light source, Kelvin }(\mathrm{K})\end{array}$ \\
\hline $1(\mathrm{\kappa})$ & All light periods -3000 \\
\hline 2 & $\begin{array}{l}\text { The first and last light periods are 3000, the } \\
\text { average light period is 5000 }\end{array}$ \\
\hline 3 & $\begin{array}{l}\text { The first and last light periods are 5000, the } \\
\text { average light period is } 3000\end{array}$ \\
\hline 4 & $\begin{array}{l}\text { All periods of light-first half-3000, second half- } \\
5000\end{array}$ \\
\hline
\end{tabular}

\footnotetext{
* Corresponding author: gdv72.72@mail.ru
} 


\section{Research results}

The results of the study (Table. 2) showed that the safety of livestock in all groups was high and amounted to 99$100 \%$, with a slight difference in the experimental group 2 .

The highest egg-laying rate for the initial and average laying hens was observed in group 3 at the color temperature of the radiation of LED lamps in the first and last periods of light was $5000 \mathrm{~K}$, and in the average period of light $-3000 \mathrm{~K}-4.6-9.6 \%$ higher than in the other groups. This indicator was minimal in the 4 experimental group, where in the first half of each light period the color temperature of the radiation was 3000 $\mathrm{K}$, and in the second half-5000 K-the lag from the 1 control group was $5.4 \%$.

A similar trend was observed in the egg weight - in the 3 experimental group it was significantly $(\mathrm{P}<0.001)$ $1.8-2.3 \%$ higher than in the other groups. The minimum egg weight was registered in the 2 and 4 experimental groups- $0.5 \%$ lower than in the 1 control group.

The weight of the eggs affected the categorization of the eggs. In group 3, with the maximum value of this indicator, the yield of eggs of the highest, selected and first categories was $1.0-1.6 \%, 2.7-3.1 \%$ and $2.1-2.6 \%$ higher, respectively, and the yield of eggs of the second category was $4.9-8.0 \%$ less than in the other groups, which did not differ significantly. The groups differed slightly in the yield of eggs of the third category and in the number of damaged eggs.

The lowest feed consumption per head per day was registered in the 4 experimental group $-2.3-5.1 \%$ lower than in the other groups. This indicator was the highest in the 3 experimental group $-2.9 \%$ more than in the 1 control group. At the same time, the lowest feed costs per 10 eggs and $1 \mathrm{~kg}$ of egg mass were obtained in the 3 experimental group - $1.4-5.5$ and $3.0-6.7 \%$ less, respectively, than in the other groups. These indicators were the highest in the 4 experimental groups -4.3 and
$5.2 \%$ higher than in the control group. The best feed conversion in the 3 experimental group was directly associated with higher egg production and egg mass yield in it.

Morphological analysis of the eggs showed (Table. 3 ) that, on average, over the period of the experiment, the absolute and relative weight of the yolk of groups 3 and 4 was $0.88-1.04 \mathrm{~g}$ and $1.04-1.05 \%$ higher than that of the control group 1 and $0.36-0.53 \mathrm{~g}$ and $0.08-0.09 \%$ higher than that of the experimental group 2. The difference in the absolute weight of the egg yolk is significant between groups 3,4 and $1(\mathrm{P}<0.001)$.

The highest absolute protein mass was observed in the 3 experimental group $-0.62-0.84 \mathrm{~g}$ higher than in the other groups. According to the relative weight of the protein, 1 control group was the leader - the superiority over the other groups was $0.44-0.86 \%$. The difference in absolute weight of the protein of eggs reliable between groups 3 and $2(\mathrm{P}<0.01)$.

Absolute and relative weight of the egg shell, 1 control group at $0.08-0.19 \mathrm{~g}$ and $0.10-0.61 \%$ was superior to the other groups, although it was noted maximum number of damaged eggs (see table. 2). Times-ness in absolute mass of eggs of reliable between groups 1 and $3(\mathrm{P}<0.05)$.

The lowest egg shell thickness was observed in the 2 experimental group-by $1.92-2.72 \%$ less than in the other groups, which did not differ significantly from each other. The difference in egg shell thickness was significant between groups 1,4 , and $2(\mathrm{P}<0.05)$.

A higher protein - to-yolk ratio was observed in control group 1-2.80 versus 2.65-2.66 in experimental groups $2-4$, which was mainly due to a lower absolute egg yolk mass in this group.

The results presented in Table 4 show that the groups differed slightly in the content of calcium in the shell (36.89-37.45\%).

The best content of vitamins in the yolk was registered in the 3 experimental group. Thus, this group

Table 2. Main results of the study.

\begin{tabular}{|l|c|c|c|c|}
\hline \multirow{2}{*}{ Indicator } & \multicolumn{3}{|c|}{ group } \\
\cline { 2 - 4 } & $\mathbf{1}(\mathbf{k})$ & $\mathbf{2}$ & $\mathbf{3}$ & $\mathbf{4}$ \\
\hline Lifestock safety, \% & 100.0 & 99.0 & 100.0 & 100.0 \\
\hline Egg production (pcs.) per laying hen: initial, & 148.64 & 141.83 & 155.46 & 140.54 \\
average & 148.64 & 142.33 & 155.46 & 140.54 \\
\hline Average egg weight, g & $61.2 \pm 0.20$ & $60.9 \pm 0.21$ & $62.3 \pm 0.19$ & $60.9 \pm 0.22$ \\
\hline Egg yield (\% ) by category: & & & & \\
the highest & 1.53 & 0.97 & 2.57 & 0.94 \\
selection & 22.54 & 22.18 & 25.28 & 22.19 \\
1 & 50.05 & 49.73 & 52.19 & 49.58 \\
2 & 17.86 & 20.67 & 12.93 & 20.94 \\
break and notch & 0.76 & 0.64 & 0.38 & 0.73 \\
Egg mass yield (kg) per laying hen: & 7.26 & 5.81 & 6.65 & 5.62 \\
Initial & & & & \\
average & 8.99 & 8.55 & 9.56 & 8.47 \\
\hline Feed consumption: & 8.99 & 8.58 & 9.56 & 8.47 \\
per 1 head per day, g & & & & \\
per 10 eggs, kg & 115.5 & 115.7 & 118.8 & 112.8 \\
per 1 kg of egg mass, kg & 1.40 & 1.46 & 1.38 & 1.45 \\
\hline
\end{tabular}


Table 3. Morphological parameters of eggs.

\begin{tabular}{|l|c|c|c|c|}
\hline \multicolumn{2}{|c|}{ Indicator } & \multicolumn{3}{c|}{ Group } \\
\cline { 2 - 5 } & $\mathbf{1}$ & $\mathbf{2}$ & $\mathbf{3}$ & $\mathbf{4}$ \\
\hline Weight: & & & & \\
egg yolk, g & $14.16 \pm 0.19$ & $14.68 \pm 0.22$ & $15.21 \pm 0.18$ & $15.04 \pm 0.15$ \\
Protein, g & 23.31 & 24.27 & 24.36 & 24.35 \\
$\%$ & $39.66 \pm 0.41$ & $38.98 \pm 0.40$ & $40.50 \pm 0.38$ & $39.88 \pm 0.34$ \\
shells, g \% & 65.30 & 64.44 & 64.86 & 64.57 \\
& $6.92 \pm 0.06$ & $6.83 \pm 0.08$ & $6.73 \pm 0.06$ & $6.84 \pm 0.06$ \\
\hline Shell thickness, microns & 11.39 & 11.29 & 10.78 & 11.08 \\
\hline Protein to yolk ratio & $367 \pm 2.5$ & $358 \pm 3.3$ & $365 \pm 3.2$ & $368 \pm 2.8$ \\
\hline
\end{tabular}

exceeded the other groups in the content of carotenoids by $23.6-43.5 \%$, vitamin A-by $6.3-14.6 \%$, vitamin E-by $18.5-44.5 \%$, vitamin B2-by $13.4-33.2 \%$. These indicators (with the exception of vitamin A) were the lowest in the 2 experimental group, although it also noted the maximum content of vitamin B2 in protein-by $2.75-7.54 \%$ higher compared to other groups.

Table 4. Results of chemical analysis of eggs.

\begin{tabular}{|l|c|c|c|c|}
\hline \multirow{2}{*}{\multicolumn{1}{|c|}{ Indicator }} & \multicolumn{4}{|c|}{ Group } \\
\cline { 2 - 5 } & $\mathbf{1 ( \kappa )}$ & $\mathbf{2}$ & $\mathbf{3}$ & $\mathbf{4}$ \\
\hline Content: & & & & \\
in the shell of & 37.45 & 37.06 & 37.21 & 36.89 \\
calcium, \% & & & & \\
in yolk, mcg / g: & & & & \\
carotenoids & 13.96 & 12.03 & 17.26 & 13.76 \\
vitamin A & 4.25 & 4.58 & 4.87 & 4.31 \\
vitamin E & 39.62 & 35.00 & 50.57 & 42.67 \\
vitamin $\mathrm{B}_{2}$ & 5.24 & 4.46 & 5.94 & 5.13 \\
vitamin $\mathrm{B}_{2}$ in the & 4.61 & 4.85 & 4.72 & 4.51 \\
protein mcg/g & & & & \\
\hline \multicolumn{4}{|r}{}
\end{tabular}

During the research, we took into account and determined the safety of the head, live weight of the bird, egg production for the initial and middle laying, egg weight, egg yield by category, feed consumption, feed costs per 10 eggs and per $1 \mathrm{~kg}$ of egg mass; the weight of protein, yolk, egg shell; shell thickness; the content of carotenoids, vitamins A, E and B2 in the yolk; vitamin $\mathrm{B} 2$ in the protein; calcium in the shell.

\section{Conclusion}

Thus, when keeping egg-laying hens in intermittent daylight conditions, 2C:5T:3C:2T:3C:9T the color temperature of the LED lights in the mode: in the first and last periods of light $5000 \mathrm{~K}$, the average period of light-3000 K compared to other tested options allowed to increase the productive qualities of chickens while reducing feed costs per unit of production.

\section{References}

1. P. Lewis, T. Morris, Lighting poultry: theory and practice, UK, Cambridge University press, 168 (2006).
2. A. R. Mukhamedshina, the effect of the light on the behavior and productivity of poultry, veterinary medicine, 6, 16-18 (2005).

3. R. Parvin, M. M. H. Mushtaq, M. J. Kim, H. C. Choi, Light emitting diode (LED) as a source of monochromatic light: lighting a novel approach for behavior, Physiology and welfare of Poultry, World's Poultry Sci. , 70(3), 557-562 (2014).

4. G. S. Archer, a Comparison of incandescent lamps, fluorescent lamps, LEDs and led lighting bird level: growth, fear and stress, international journal of poultry, 14, 449-455 (2015).

5. H. H. Mohammed, assessment of the role of light in the welfare of the layers SVU - international journal of veterinary Sciences, 2(1), 36-50, 2019.

6. V. I. Fisinin, A. sh. Kavtarashvili, S. A. Imangulov, Biological bases of increase of efficiency of production of chicken eggs, Sergiev In the garden, 182 (1999).

7. A. S. Kavtarashvili, His Majesty the light-the fundamental factor in egg poultry farming, Poultry and Poultry products, 5, 45-47 (2007)

8. Novoselov, I. M. Development and justification of the efficiency of technological LED lighting of the poultry house of an industrial flock of laying hens, dis. ... Candidate of Technical Sciences, Izhevsk, 132 (2011)

9. P. D. Lewis, T. R. Morris, Poultry and colored light, World's Poultry Sci. J., 6, 189-207 (2000).

10. H. A. Olanrewaju, J. P. Thaxton, W. A. Dozier III, J. Purswell, W. B. Roush, S. L. Branton, A review of lighting programs for broiler production, Int. J. Poult. Sci., 4, 301-308 (2006).

11. M. J. Zuidhof, Effects of light intensity on the photostimulation in four strains of commercial layers eggs: 2. Parameters of egg production, Poultry farming, 80, 1121-1131 (2001).

12. Olanrewaju, H. A., W. W. Miller, W. R. Maslin, S. D. Collier, J. L. Pur-swell, S. L. Branton, Effects of light sources and intensity on broilers raised to heavy weights. Part 1: growth performance, carcass characteristics and indicators of well-being, Science of poultry, 95 (4), 727-735 (2016). 
13. V. I. Fisinin, A. Sh. Kavtarashvili, E. N. Novatorov, D. V. Gladin, Local led lighting as a way to enhance the efficiency of poultry production Achievements of science and technology of AIC, 6, 61-63 (2011).

14. R. Borille, R. G. Garcia, A. F. B. Royer, M. R. Santana, S. Colet, I. A. Naas, F. R. Caldara, I. C. L. Almeida Paz, E. S. Rosa, V. A. R. Castilho, The use of light-emitting diodes (LED) in commercial layer production, Rev. Bras. Sienc. Avic., 15, 135-140 (2013).

15. H. A. Olanrewaju, J. L. Purswell, V. R. Maslin, S. D. Collier, S. L. Brunton, the Effect of color temperature (Kelvin) led bulbs on the growth performance, carcass characteristics and indicators of eye development of broilers grown to heavy weights, Poultry, 94 (3), 338-344 (2015).

16. R. Hasan, S. Sultan, S. H. Choi, K. S. Ryu, the Impact of combinations of monochromatic led light colors on the performance and behaviour of laying hens, John. Sci, 51 (3), 321-326 (2014).

17. W. B. B. Morrill, J. C. M. Barnabé, T. P. N. Da Silva et al., The effect of monochromatic and polychromatic led RGB lighting on the growth, behaviour and development of broilers, proceedings of the Society of engineers photooptical engineering, San Francisco, California, USA. Wellington, 2014.

18. B. Huber-Eicher, A. Suter,d P. Spring-Stähli, The influence of color LED lighting on the behavior and productivity of laying hens, Poult. Sci. 92(4), 869873 (2013).

19. G. S. Archer. The color temperature of LED lighting is important for the optimal growth and well-being of broiler chickens, animals. 12(5), 1015-1021 (2018).

20. J. Svobodova, E. Túmova, E. popelbřova, D. Chodova, Effect of light col-our on egg production and egg contamination, Czech J. Anim. Sci., 60(12), 550-556 (2015). 